\title{
Clinical Case Series of Decrease in Shear Wave Elastography Values in Ten Diabetic Dyslipidemia Patients Having NAFLD with Saroglitazar 4 mg: An Indian Experience
}

\author{
Sayak Roy \\ Dept. of Internal Medicine, Medica Superspeciality Hospital, Kolkata, India \\ Correspondence should be addressed to Sayak Roy; sayak.roy.123@gmail.com
}

Received 18 July 2019; Revised 4 February 2020; Accepted 26 February 2020; Published 28 March 2020

Academic Editor: Lothar Bergmann

Copyright (C) 2020 Sayak Roy. This is an open access article distributed under the Creative Commons Attribution License, which permits unrestricted use, distribution, and reproduction in any medium, provided the original work is properly cited.

\begin{abstract}
Background. Diabetes and other metabolic abnormalities including high triglycerides (TGs) are commonly seen comorbid conditions in patients having nonalcoholic fatty liver disease (NAFLD). There is no approved pharmacotherapy for NAFLD, and life-style therapy plays a major role. Saroglitazar, the world's first approved dual PPAR $\alpha / \gamma$ agonist, is approved in India for the treatment of diabetic dyslipidemia. The objective of this case series analysis was to evaluate the safety and effectiveness of saroglitazar $4 \mathrm{mg}$ once daily in reducing liver stiffness in patients having diabetic dyslipidemia associated NAFLD. Method. In this retrospective case series analysis, we identified 10 patients with diabetic dyslipidemia (type 2 diabetes and triglycerides $>200 \mathrm{mg} /$ $\mathrm{dL}$ at baseline) and NAFLD who were treated with saroglitazar $4 \mathrm{mg}$ once daily and the follow-up data were available for 9 months after saroglitazar treatment. At baseline, all patients were on stable antidiabetic and statin therapy. Liver stiffness was measured by using 2D shear wave elastography at baseline and at 9-month follow-up. Results. At 9-month follow-up after saroglitazar treatment, significant improvement was observed in shear wave velocity (SWV) and serum transaminases levels. Serum TG level was significantly reduced after 9-month treatment with saroglitazar. No major adverse event was reported. Conclusion. In this case series of 10 patients with diabetic dyslipidemia and NAFLD, saroglitazar improved liver stiffness along with reduction observed in liver enzymes and TG values. Long-term randomized controlled clinical trial is required to further establish the safety and efficacy of saroglitazar in treatment of NAFLD.
\end{abstract}

\section{Background}

Nonalcoholic fatty liver disease (NAFLD) is projected to become the leading cause of liver transplantation [1]. Insulin resistance has been considered as a core pathophysiological factor in NAFLD [2]. There has been a strong association observed between NAFLD and type 2 diabetes mellitus (T2DM), and the studies have shown that $>70 \%$ of patients with T2DM will have NAFLD [3]. In NAFLD, the risk of liver-related mortality increases exponentially with increase in fibrosis stage [4]. The recommended gold standard in the diagnosis and staging of liver fibrosis is liver biopsy, but it is invasive. The use of shear wave elastography (SWE) in the diagnosis and staging of liver fibrosis has been increasing. The SWE method uses the values of acoustically produced SW propagation speeds in the liver tissue then estimates the liver stiffness [5].

Currently, there is no FDA approved pharmacotherapy for T2DM patients with associated NAFLD/NASH. Saroglitazar is the first approved dual PPAR $\alpha / \gamma$ agonist, approved in India for the treatment of diabetic dyslipidemia [6]. Here we retrospectively analyse the case series of 10 type 2 diabetic patients who also had dyslipidemia with NAFLD and were treated with saroglitazar $4 \mathrm{mg}$ once daily for the period of 9 months.

\section{Materials and Methods}

We retrospectively identified the database of patients who had been prescribed saroglitazar $4 \mathrm{mg}$ (Lipaglyn $^{\mathrm{TM}}$, from Cadila Healthcare Ltd, containing saroglitazar magnesium) 
for the treatment of diabetic dyslipidemia from author's clinic. We selected patients on the following criteria for this case series analysis:

(1) Patients with type $2 \mathrm{DM}$ having TG $>200 \mathrm{mg} / \mathrm{dL}$ whose baseline and 9-month posttreatment parameters were available

(2) Presence of NAFLD (defined sonographycally and from history) and underwent shear wave elastography for liver stiffness assessment

(3) Treated with saroglitazar magnesium $4 \mathrm{mg}$ once daily

(4) No use of GLP1 analogue or SGLT2I or pioglitazone in the population during the assessment period or 3 months prior to assessment

(5) No history of liver injury by any chemicals or drugs during the 9 months of assessment period

(6) Hepatitis B and Hepatitis C negative status

(7) On stable therapy for any chronic disease for $>6$ months prior to recruitment

Shear wave elastography machine used for liver stiffness assessment was Philips Affinity $70^{\circledR}$ using 2 dimensional imaging. This technology measures shear wave velocity (SWV) using acoustic radiation force impulse (ARFI) (Table 1).

2.1. Statistical Analysis Applied. The statistical analysis was done using GraphPad insta online version ${ }^{\circledR}$ (https://www. graphpad.com/quickcalcs/ttest1/) and results were analysed applying paired $t$ test. A $P$ value of $<0.05$ was taken as statistically significant.

\section{Results}

We analysed a total of 10 patients (male: female $7: 3$ ) with mean age of 59.3 years with average duration of diabetes 8.8 years (Table 2). The mean baseline HbA1c and TG values were $7.8 \%$ and $298.2 \mathrm{mg} / \mathrm{dL}$, respectively (Table 3 ). All these patients were already on stable dose of statin therapy and antidiabetic therapy at baseline. They all were prescribed saroglitazar $4 \mathrm{mg}$ once daily. The baseline and 9-month follow-up data were analysed after adding saroglitazar therapy.

The mean baseline SWV value $1.837 \pm 0.0691 \mathrm{~m} / \mathrm{s}$ was reduced significantly to $1.645 \pm 0.0844 \mathrm{~m} / \mathrm{s}$ at 9 -month follow-up after saroglitazar treatment (Table 3; Figure 1). At 9month follow-up after saroglitazar, the HbA1c level was significantly reduced from $7.8 \pm 0.343 \%$ to $6.9 \pm 0.33 \%$ $(P<0.0001)$. Serum TG was also significantly reduced from $298.2 \pm 35.75 \mathrm{mg} / \mathrm{dL}$ to $202.4 \pm 13.19 \mathrm{mg} / \mathrm{dL}(P<0.0001)$ at 9-month follow-up. Liver enzymes, ALT, and AST were also reduced significantly from baseline at 9-month follow-up after saroglitazar treatment (Table 3).

\section{Discussion}

Obesity, insulin resistance, and other metabolic abnormalities including high TG are very closely related to NAFLD. Recently, a retrospective study showed a huge
TABLE 1: ARFI (acoustic radiation force impulse) values for liver stiffness by SWE.

\begin{tabular}{lc}
\hline ARFI grade & ARFI values $(\mathrm{m} / \mathrm{sec})$ \\
\hline Normal & $1.0-1.5$ \\
Mild fibrosis & $1.5-1.75$ \\
Moderate fibrosis & $1.75-2.1$ \\
Severe fibrosis & $>2.1$ \\
\hline
\end{tabular}

burden of liver fat score as measured by SWE in our T2DM patients having NAFLD [7]. Current guidelines recommend that the management of NAFLD should consist of treating liver disease as well as the associated metabolic comorbidities such as obesity, hyperlipidemia, insulin resistance, and T2DM [8]. Saroglitazar has been studied in India in patients with diabetic dyslipidemia during phase III RCTs [9]. Saroglitazar significantly improves insulin resistance by its action on PPAR $\gamma$ receptor [10]. This study showed significant improvement in SWV values with additional improvements in metabolic parameters (HbAlc, TG and HDL-C) with 9-month treatment with saroglitazar. Saroglitazar also improved serum transaminases levels at 9-month treatment. In this case series, saroglitazar treatment was not associated with increase in BMI and waist circumference (Table 3) at 9month follow-up.

4.1. Limitations of This Case Series. The sample size was small to deduce any proper conclusion. There was no chance of intervention in life-style changes, and hence, the differences in SWV value reduction cannot be properly attributed to the molecule per se. The robust reduction of HbAlc might be attributed to the change in other oral hypoglycemic drugs whose doses were increased to meet the HbAlc target of $7 \%$.

4.2. Summary. In this case series, 9-month treatment with saroglitazar showed significant reduction in SWV values along with improvement in metabolic parameters (blood glucose, TG, and HDL-C levels) without causing weight gain in Indian type 2 diabetic dyslipidemia patients with NAFLD. This is a retrospective case series analysis of only 10 patients, and a large randomized controlled clinical trial is needed to establish the safety and efficacy of saroglitazar in patients with NAFLD.

\section{Consent}

Informed consent has been taken by the author from all 10 cases analysed in this case series.

\section{Disclosure}

The abstract of this study was presented as an E-poster viewing at the Advanced Technologies and Treatments for Diabetes held in Madrid, Spain (2020). 
TABLE 2: Baseline characteristics.

\begin{tabular}{|c|c|c|c|c|c|c|c|c|c|c|c|}
\hline $\begin{array}{l}\text { Sr. No. of } \\
\text { patient }\end{array}$ & $\begin{array}{l}\text { Age } \\
\text { (yrs) }\end{array}$ & Sex & $\begin{array}{c}\text { BMI } \\
\left(\mathrm{kg} / \mathrm{m}^{2}\right)\end{array}$ & $\begin{array}{c}\text { Waist } \\
\text { circum } \\
\text { (inches) }\end{array}$ & $\begin{array}{l}\text { Duration of } \\
\text { T2DM (yrs) }\end{array}$ & $\begin{array}{c}\mathrm{HbA} 1 \mathrm{c} \\
\%\end{array}$ & $\begin{array}{c}\text { TG } \\
(\mathrm{mg} / \mathrm{dL})\end{array}$ & $\begin{array}{l}\text { ALT } \\
(\mathrm{U} / \mathrm{L})\end{array}$ & $\begin{array}{l}\text { AST } \\
(\mathrm{U} / \mathrm{L})\end{array}$ & $\begin{array}{l}\text { HDL-C } \\
(\mathrm{mg} / \mathrm{dL})\end{array}$ & $\begin{array}{c}\text { Systolic blood } \\
\text { pressure }(\mathrm{mmHg})\end{array}$ \\
\hline 1 & 52 & $\mathrm{M}$ & 26.5 & 40.5 & 7 & 7.9 & 330 & 68 & 66 & 35 & 132 \\
\hline 2 & 55 & $\mathrm{M}$ & 27 & 41 & 10 & 8.1 & 280 & 88 & 43 & 43.2 & 138 \\
\hline 3 & 63 & $\mathrm{M}$ & 29.3 & 41.1 & 11 & 8.3 & 311 & 54 & 42 & 40 & 142 \\
\hline 4 & 64 & $\mathrm{M}$ & 25.3 & 40 & 8 & 7.9 & 270 & 67 & 39 & 37 & 134 \\
\hline 5 & 53 & $\mathrm{M}$ & 22.4 & 39.8 & 7 & 7.2 & 298 & 71 & 39 & 45 & 136 \\
\hline 6 & 57 & $\mathrm{~F}$ & 21.5 & 35 & 8 & 7.4 & 252 & 81 & 43 & 48 & 128 \\
\hline 7 & 61 & $\mathrm{~F}$ & 27.6 & 34.3 & 9 & 7.8 & 307 & 41 & 28 & 46.2 & 126 \\
\hline 8 & 62 & $\mathrm{~F}$ & 22.5 & 35.1 & 8 & 8.1 & 263 & 69 & 56 & 45.5 & 142 \\
\hline 9 & 67 & $\mathrm{M}$ & 28.8 & 33.2 & 10 & 7.8 & 297 & 68 & 40 & 37 & 138 \\
\hline 10 & 59 & $\mathrm{M}$ & 21.2 & 36 & 10 & 7.5 & 374 & 40 & 38 & 31 & 144 \\
\hline
\end{tabular}

TABLE 3: Change in biochemical/clinical parameters and SWV values at baseline and after 9-month treatment with Saroglitazar 4 mg once daily.

\begin{tabular}{|c|c|c|c|c|}
\hline & Baseline & 9 months & Change from baseline & $P$ value \\
\hline Waist circumference (inches) & $37.6 \pm 3.138$ & $37.51 \pm 3.123$ & -0.09 & 0.54 \\
\hline BMI $\left(\mathrm{kg} / \mathrm{m}^{2}\right)$ & $25.21 \pm 3.07$ & $24.81 \pm 2.95$ & -0.4 & 0.046 \\
\hline $\mathrm{FBG}(\mathrm{mg} / \mathrm{dL})$ & $139.5 \pm 15.67$ & $106.5 \pm 14.94$ & -33 & $<0.0001$ \\
\hline HbAlc (\%) & $7.8 \pm 0.343$ & $6.9 \pm 0.33$ & -0.9 & $<0.0001$ \\
\hline $\mathrm{TG}(\mathrm{mg} / \mathrm{dL})$ & $298.2 \pm 35.75$ & $202.4 \pm 13.19$ & -95.8 & $<0.0001$ \\
\hline HDL-C (mg/dL) & $40.79 \pm 5.63$ & $45.2 \pm 4.36$ & 4.4 & 0.0007 \\
\hline $\operatorname{ALT}(\mathrm{U} / \mathrm{L})^{\circ}$ & $64.7 \pm 15.56$ & $46.2 \pm 12.6$ & -18.5 & 0.0058 \\
\hline AST $(\mathrm{U} / \mathrm{L})$ & $43.4 \pm 10.48$ & $35.4 \pm 6.59$ & -8 & 0.0321 \\
\hline SWV $(\mathrm{M} / \mathrm{S})$ & $1.837 \pm 0.0691$ & $1.645 \pm 0.0844$ & -0.192 & 0.0004 \\
\hline $\mathrm{SBP}(\mathrm{mmHg})$ & $136 \pm 6.04$ & $134.6 \pm 7.24$ & -1.4 & 0.0445 \\
\hline
\end{tabular}

$n=10$; data are mean \pm SD; paired " $t$ " test.

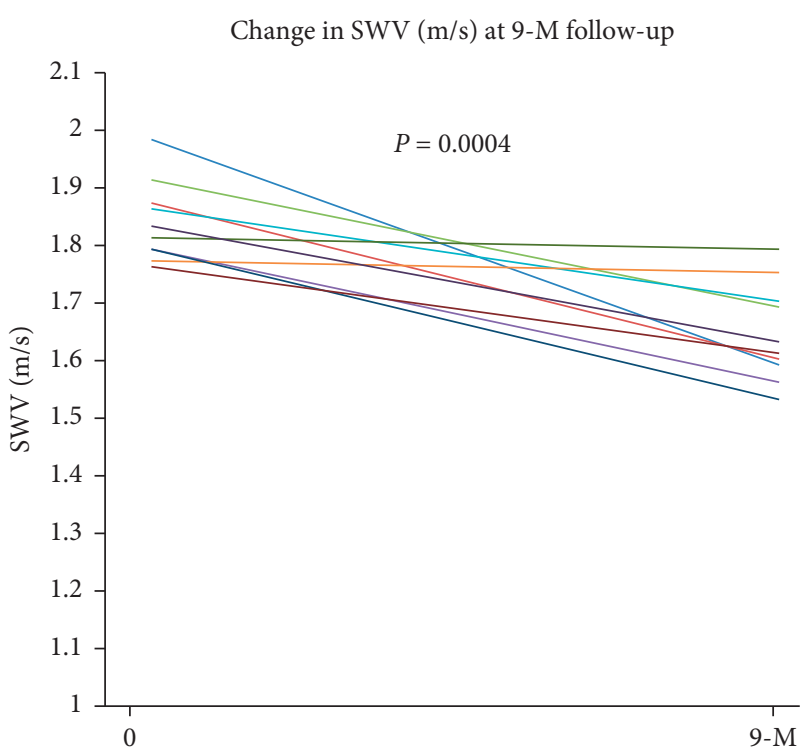

FIGURE 1: SWV of 10 patients at baseline and after 9-month treatment with saroglitazar.

\section{Conflicts of Interest}

The author has no conflicts of interest.

\section{Acknowledgments}

The abstract of this study was presented as an E-poster viewing at the Advanced Technologies and Treatments for Diabetes held in Madrid, Spain (2020).

\section{References}

[1] R. J. Wong, M. Aguilar, R. Cheung et al., "Nonalcoholic steatohepatitis is the second leading etiology of liver disease among adults awaiting liver transplantation in the United States," Gastroenterology, vol. 148, no. 3, pp. 547-555, 2015.

[2] G. Marchesini, M. Brizi, A. M. Morselli-Labate et al., "Association of nonalcoholic fatty liver disease with insulin resistance," The American Journal of Medicine, vol. 107, no. 5, pp. 450-455, 1999.

[3] C. D. Williams, J. Stengel, M. I. Asike et al., "Prevalence of nonalcoholic fatty liver disease and nonalcoholic steatohepatitis among a largely middle-aged population utilizing ultrasound and liver biopsy: a prospective study," Gastroenterology, vol. 140, no. 1, pp. 124-131, 2011.

[4] P. S. Dulai, S. Singh, J. Patel et al., "Increased risk of mortality by fibrosis stage in nonalcoholic fatty liver disease: systematic review and meta-analysis," Hepatology, vol. 65, no. 5, pp. 1557-1565, 2017.

[5] N. Frulio and H. Trillaud, "Ultrasound elastography in liver," Diagnostic and Interventional Imaging, vol. 94, no. 5, pp. 515-534, 2013. 
[6] S. R. Joshi, "Saroglitazar for the treatment of dyslipidemia in diabetic patients," Expert Opinion on Pharmacotherapy, vol. 16, no. 4, pp. 597-606, 2015.

[7] S. Roy and A. Majumder, "A retrospective study to examine the correlation of bioelectrical impedance analysis with shearwave elastography in Indian patients with non-alcoholic fatty liver disease and diabetes on background sodium-glucose cotransporter-2 inhibitor therapy," Cureus, vol. 11, no. 5, Article ID e4674, 2019.

[8] N. Chalasani, Z. Younossi, J. E. Lavine et al., "The diagnosis and management of nonalcoholic fatty liver disease: practice guidance from the American association for the study of liver diseases," Hepatology, vol. 67, no. 1, pp. 328-357, 2018.

[9] V. Pai, A. Paneerselvam, S. Mukhopadhyay et al., "A multicenter, prospective, randomized, double-blind study to evaluate the safety and efficacy of saroglitazar 2 and $4 \mathrm{mg}$ compared to pioglitazone $45 \mathrm{mg}$ in diabetic dyslipidemia (PRESS V)," Journal of Diabetes Science and Technology, vol. 8, no. 1, pp. 132-141, 2014.

[10] M. R. Jain, S. R. Giri, C. Trivedi et al., "Saroglitazar, a novel $\operatorname{PPAR} \alpha / \gamma$ agonist with predominant PPAR $\alpha$ activity, shows lipid- lowering and insulin-sensitizing effects in preclinical models," Pharmacology Research \& Perspectives, vol. 3, no. 3, Article ID e00136, 2015. 